\title{
Production and processing asymmetries in the acquisition of tense morphology by sequential bilingual children
}

Article

Accepted Version

Chondrogianni, V. and Marinis, T. (2012) Production and processing asymmetries in the acquisition of tense morphology by sequential bilingual children. Bilingualism: Language and Cognition, 15 (1). pp. 5-21. ISSN 1469-1841 doi: https://doi.org/10.1017/S1366728911000368 (Special Issue 01 Bilingual children with specific language impairment) Available at https://centaur.reading.ac.uk/26604/

It is advisable to refer to the publisher's version if you intend to cite from the work. See Guidance on citing.

To link to this article DOI: http://dx.doi.org/10.1017/S1366728911000368

Publisher: Cambridge University Press

All outputs in CentAUR are protected by Intellectual Property Rights law, including copyright law. Copyright and IPR is retained by the creators or other copyright holders. Terms and conditions for use of this material are defined in the End User Agreement. 


\section{CentAUR}

Central Archive at the University of Reading

Reading's research outputs online 
Running Head: Asymmetries in the acquisition of tense in L2 children

\section{Production and processing asymmetries in the acquisition of tense morphology by sequential bilingual children}

Vasiliki Chondrogianni \& Theodoros Marinis

University of Reading, School of Psychology \& Clinical Language Sciences, UK

*This research was supported by the Economic and Social Research Council research grant

'Real-time processing of syntactic information in children with English as a Second Language \& children with Specific Language Impairment' awarded to Theo Marinis (RES061-23-0137). We would like to thank Halit Firat for collecting the data from the L2 children, the schools and families for participating in this project, and two anonymous reviewers for their constructive comments and suggestions.

Address for correspondence:

Vasiliki Chondrogianni

University of Reading

School of Psychology and Clinical Language Sciences

Reading RG6 6AL, UK

E-mail: v.chondrogianni@reading.ac.uk

Keywords: tense morphemes, L2 children, production, on-line processing 


\begin{abstract}
This study investigates the production and on-line processing of English tense morphemes by sequential bilingual (L2) Turkish-speaking children with more than three years of exposure to English. Thirty nine 6-9-year-old L2 children and 28 typically developing age-matched monolingual (L1) children were administered the production component for third person $-s$ and past tense of the Test for Early Grammatical Impairment (Rice \& Wexler, 1996) and participated in an on-line word-monitoring task involving grammatical and ungrammatical sentences with presence/omission of tense (third person $-s$, past tense $-e d$ ) and non-tense (progressive -ing, possessive 's) morphemes. The L2 children's performance on the on-line task was compared to that of children with Specific Language Impairment (SLI) in Montgomery \& Leonard $(1998,2006)$ to ascertain similarities and differences between the two populations. Results showed that the L2 children were sensitive to the ungrammaticality induced by the omission of tense morphemes, despite variable production. This reinforces the claim about intact underlying syntactic representations in child L2 acquisition despite non target-like production (Haznedar \& Schwartz, 1997).
\end{abstract}




\section{INTRODUCTION}

The acquisition of inflectional morphology is notoriously difficult for both adult and child second language (L2) learners. One of the longstanding questions in L2 acquisition studies with child and adult L2 learners has been whether or not non target-like production of morphology reflects impaired grammatical representations (Hawkins \& Chan, 1997; Haznedar \& Schwartz, 1997; Vainikka \& Young-Scholten, 1996a). To address this question, we compared sequential bilingual children's acquisition of morpho-syntax with that of monolingual (L1) typically-developing (TD) children. More recently, studies have compared L2 children's performance with that of children with Specific Language Impairment (SLI) and have found similarities between the two groups in the production of French clitic pronouns and English tense morphemes' e.g. Paradis (2004) and Paradis, Rice, Crago \& Marquis (2008). This line of research has focused primarily on production tasks and the L2 children in the above studies had less than three years of exposure. Very few recent studies have investigated the morpho-syntactic abilities of L2 children with more than three years of exposure using production (Marinis \& Chondrogianni, 2010), off-line comprehension (Grüter, 2005; Marinis \& Chondrogianni, 2011), and on-line comprehension tasks (Marinis, 2007; Marinis, 2008). These have shown that L2 children with more than three years of exposure are less impaired in the production of tense morphology than previously reported (Marinis \& Chondrogianni, 2010) and perform similarly to L1 children in the off-line and online comprehension of two phenomena studied: 1) reflexive and non-reflexive pronouns (Marinis, 2008; Marinis \& Chondrogianni, 2011) and 2) passives (Marinis, 2007). However, there is no research to date investigating whether or not L2 children who omit tense morphemes in their production process the ungrammaticality induced by the omission of tense morphemes when they listen to sentences in real-time. 
The present paper addresses this issue by examining the production and on-line processing of tense morphemes in 6-to-9-year-old L2 children acquiring English in comparison to agematched L1 children and children with SLI from Montgomery \& Leonard (1998, 2006). The L2 children in the present paper have three or more years of exposure to English and in this respect differ from previous studies which have investigated children with limited exposure, i.e. less than two years (Paradis et al., 2008) or with a wide age range at the time of testing (Ionin \& Wexler, 2002). Furthermore, a production task is employed in conjunction with an on-line processing task to explore the relationship between production and on-line comprehension abilities of the L2 children. This enables us to address opposing L2 acquisition theories regarding the relationship between overt morphology and underlying syntax (Haznedar \& Schwartz, 1997; Vainikka \& Young-Scholten, 1996b, 1998a, 1998b, 2010). In addition, it allows us to examine whether the low performance of the L2 children and the children with SLI in production tasks (Paradis, 2005) reflects similar processing systems and underlying grammatical representations.

Before we examine the literature on the acquisition of tense morphemes in English by child L2 learners, we will briefly describe the tense systems of English and Turkish, the languages spoken by the L2 children in our study.

\section{Tense in English and in Turkish}

English uses both bound (examples 1a and 1b) and unbound (examples 1c and 1d) morphemes to indicate tense and subject-verb agreement. Third person $-s$ on lexical/thematic verbs marks person and number, as shown in (1a) and gives rise to a morpho-phonologically poor agreement paradigm, as only third person singular $-s$ is overtly marked with the other persons carrying zero morphology in both the plural and the singular. In this respect, third 
person $-s$ in English encodes the features [-past], [3p], and [+sing]. Person and number are also marked on the suppletive forms of the copula and the auxiliary be and the dummy auxiliary do morphemes, as shown in (1c) and (1d). The feature [+past] is indicated by a consistent morpho-phonological marking of the regular suffix -ed in the case of regular past tense, as shown in (1b), which does not vary depending on the form of the subject, whereas irregular past tense consists of suppletive forms, as shown in (1e). The morpheme -ing marks progressive aspect, as shown in (1f).

1. a. Peter walks to school.
b. Jane kicked the ball.
c. Mary is happy.
d. Do you like cakes?
e. Gerry threw the ball.
f. Peter is walking to school.

In contrast to the poor morphological paradigm in English, Turkish is an agglutinating language with a rich morphological paradigm. Turkish has separate suffixes indicating tense and agreement, which follow a strict order, i.e. tense preceding agreement marking. In addition, Turkish has a quite transparent one-to-one form-meaning mapping (Göksel \& Kerslake, 2005). There are six different forms in the verbal paradigm marking person, and person is marked both on present and past tense, as in (2a) and (2b).

2. a. gel-iyor -um. 


\author{
'I am going' \\ b. gel-d -im. \\ Go-PAST-1SG
}

'I went'

Important for the present study is that Turkish-speaking L2 children will need to move from a rich yet transparent morphological paradigm with strict suffixal order to a system where features corresponding to the Tense category have fusional or zero morpho-phonology.

\title{
L1 acquisition of English tense morphemes by typical and atypical children
}

English TD L1 children have been shown to acquire grammatical morphemes by their fourth year of age (Brown, 1973). In relation to verbal morphemes, longitudinal and cross-sectional morpheme order studies have reported that the progressive suffix -ing is one of the first morphemes to be acquired, whereas auxiliary $b e$, regular past tense $-e d$, and third person $-s$ are the last ones (Brown, 1973; de Villiers \& de Villiers, 1973). Turning to the acquisition of tense marking morphemes, it is by now well documented that English TD L1 children pass through a stage up until their third year of age when they optionally produce tense morphemes, as in the examples (3a) to (3c) below:

3. a. Everyday she bake(s) cakes.

b. He (is) happy.

c. Yesterday he paint(ed) the fence. 
This stage has been called the Optional Infinitive (OI) stage and has been documented in non-null subject languages (Wexler, 1998). The OI stage is marked by the optional production of tense related morphology, although children seem to know the morphosyntactic contingencies associated with the underlying functional categories for tense and no form choice errors are found (Wexler, 1994). That is, L1 children rarely produce errors such as I eats instead of I eat. Additionally, L1 children produce an unmarked verb form with a correctly marked nominative subject pronoun, indicating that the subject has successfully moved to the specifier of the Tense Phrase (TP), and thus, the underlying Tense category is present in their syntactic representation.

The OI stage reported for the TD L1 children is also well documented in children with SLI, who exhibit a protracted or extended optional infinitive (E)OI stage and even by the age of nine years optionally produce tense-marking morphology (Rice, Wexler, \& Hershberger, 1998). At the same time and similarly to TD children, children with SLI make limited form choice errors and do not exhibit problems with non tense related morphology, such as progressive -ing or plural $-s$ (Rice, Wexler, \& Hershberger, 1998). These results suggest that grammatical morphemes are selectively affected in children with SLI, as tense marking morphology is impaired whereas non tense morphemes are not.

This impairment seems to extend beyond production into comprehension for both younger (Rice, Wexler, \& Redmond, 1999) and older children with SLI (Montgomery \& Leonard, 1998, 2006). Rice, Wexler, \& Redmond (1999) used a grammaticality judgment task with 6;0 to $8 ; 11$ year old children with SLI and two groups of language-matched (age range: $4 ; 0-$ $5 ; 11)$ and age-matched unaffected L1 children to ascertain whether the difficulties that children with SLI face with production also reflect impaired representations. The TD language-matched controls who were at the end of the OI stage were likely to accept 
uninflected verbs as grammatical, but the group showed sharp progress towards the end of the OI stage (they moved from A-prime score $=0.65$ to 0.90 during the testing period). ${ }^{1}$ This was also confirmed by the age-matched group, whose performance was above 0.90 when testing began and reached ceiling at the end of the testing period. The SLI group's performance, on the other hand, improved over time, but failed to reach age-appropriate norms by the end of the testing period and averaged around 0.65 to 0.70 for ages six to seven years. Conversely, the children with SLI were sensitive at detecting the ungrammaticality in the case of a dropped progressive -ing marker, similarly to the language-matched and the age-matched children, and by the age of seven years they were at an A-prime score of 0.90 and above.

Furthermore, there was a strong similarity between the growth curves observed in the production (Rice, Wexler, \& Hershberger, 1998) and the grammaticality judgment studies for both the TD children and the children with SLI, suggesting that in both impaired and unimpaired L1 acquisition, production and comprehension of grammatical morphemes develop in parallel.

These results from the grammaticality judgment task from Rice et al. (1999) were confirmed in two studies with older children with SLI and age-matched controls between the ages of 6;7 - 10;5 (mean age: 9;0) by Montgomery \& Leonard (1998, 2006). In these studies, children with SLI showed a significantly lower sensitivity to third person $-s$ and past tense $e d($ A-prime score $=0.87)$ compared to the age-matched children $(\mathrm{A}$-prime score $=0.95)$, but

\footnotetext{
${ }^{1}$ A-prime scores are formula-converted scores which are calculated on the basis of the proportion of hits (correct acceptances of grammatical targets) and false alarms (incorrect rejections of grammatical targets) in a grammaticality judgment task. In this way, children's potential bias towards 'yes' responses is corrected for (Rice et al., 1999).
} 
the two groups did not differ in detecting the ungrammaticality in the case of the progressive -ing marker.

To ascertain whether SLI children's impaired production and judgment of grammatical morphology is also reflected in the way they process grammatical morphemes in real-time, Montgomery \& Leonard $(1998,2006)$ carried out an on-line word-monitoring task. In this task, children saw a picture at the beginning of each trial and then they listened to a sentence containing the word that goes with the picture that they saw at the beginning, as in 'John mother's is a great baker. Most nights she bake(s) cakes for him and the whole family'. The task of the participant was to press a button as fast as possible, when they heard in the sentence the word corresponding to the picture they saw at the beginning of the trial. The word-monitoring task comprised sentences with present or omitted inflectional morphemes on a critical word (bake(s)), and the monitored word (cakes) appeared after the inflected or uninflected critical word. If children with SLI are sensitive to the ungrammaticality induced by the omission of grammatical morphemes, then their Reaction Times (RTs) should be longer in sentences containing omission of the grammatical morpheme vs. the ones with the grammatical morpheme present.

Results showed that the TD children exhibited longer RTs in sentences with omission of grammatical morphemes compared to sentences containing grammatical morphemes, and thus, demonstrated sensitivity to the omission of grammatical morphemes. In contrast, children with SLI were sensitive to the omission of the progressive -ing, but not to the omission of third person $-s$, past tense $-e d$, and possessive $-s$. Additionally, the children with SLI had significantly longer RTs than the TD children. According to Montgomery \& Leonard $(1998,2006)$ these findings suggest that children with SLI have difficulties with processing grammatical morphemes that have low phonetic substance. 


\section{Acquisition of tense morphology by child L2 learners}

Studies with impaired and unimpaired L1 children have shown that tense morphemes are acquired after non tense morphemes and that the production and comprehension of these morphemes exhibit parallel growth curves. In contrast, the findings from studies with L2 children indicate a somewhat different pattern. A variable production of tense vs. non tense morphemes in L2 acquisition has been documented in various studies (Dulay \& Burt, 1973; Dulay, Burt, \& Krashen, 1982; Haznedar, 2001; Jia \& Fuse, 2007; Zobl \& Liceras, 1994). Progressive -ing is one of the first morphemes to be acquired in child L2 acquisition, similarly to L1 acquisition, but third person singular $-s$ and regular past tense $-e d$ have a protracted and uneven acquisition pattern and may not reach target-like production even after five years of exposure, as documented in the longitudinal study with Mandarin learners of English by Jia \& Fuse (2007). At the same time, L2 learners seem to be able to acquire the morpho-syntactic contingencies related to the underlying syntactic category of Tense, such as nominative case marking on subject pronouns (Haznedar, 2001; Prévost \& White, 2000). For example, Haznedar (2001) studied a four-year old Turkish boy, who after eighteen months of exposure to English produced third person $-s$ and past tense $-e d$ in less than $80 \%$ and $60 \%$ of obligatory contexts respectively indicating an asymmetry in the acquisition of the two morphemes, whereas correctly case marked pronominal subjects appeared after four months of exposure in most obligatory contexts, suggesting intact underlying functional categories related to Tense.

Given the observed low production of tense morphology, a central debate in the L2 acquisition research questions whether or not low or optional overt morphological marking reflects impaired underlying grammatical competence. Two main lines of thought have 
addressed this issue suggesting a competing relationship between (overt) morphology and syntax (White, 2003: 1) the syntax-before-morphology account, such as the Missing Surface Inflection Hypothesis (MSIH) (Haznedar, 2001; Lardiere, 1998a, 1998b; Prévost \& White, 2000), and 2) the morphology-before-syntax accounts, encompassing theories such as the Failed Functional Features Hypothesis (FFFH) (Hawkins \& Chan, 1997; Hawkins \& Hattori, 2006), the Interpretability Hypothesis (IH) (Tsimpli, 2003), and the Minimal Trees Hypothesis (MTH) (Vainikka \& Young-Scholten, 1996a, 1996b, 1998a, 1998b, 2010).

The MSIH is articulated on the basis of a separation view of morphology (Halle \& Marantz, 1993), according to which a distinction should be made between the acquisition of morphology and the acquisition of syntax. This account argues that the optional use of overt morphological expression does not entail lack of underlying syntactic structure. Rather, there is a mapping problem between overt morphological expression and the underlying syntax (Haznedar \& Schwartz, 1997; Lardiere, 1998a, 1998b; Prévost \& White, 2000). More recently, Lardiere $(2005 ; 2009)$ proposed that what may be problematic for L2 learners is not the mere presence of a functional category or a feature in the $\mathrm{L} 1$, but rather the way these categories and features are reassembled into the right lexical items in the L2. The task of the L2 learner is to successfully (re)assemble features (un)available in the L1 according to the L2 specifications. This account is also compatible with a separation view of morphology and it implies that feature (re)assembly applies at more abstract levels of representation and that missing or default surface inflection does not indicate (re)assembly problems, similarly to the MSIH (White, 2009). In this respect, Lardiere's (2005; 2009) account also postulates an asymmetry between production and the presence of underlying grammatical representations. Furthermore, this account takes into consideration the (re)assembly of the morpho- 
phonological expression of these formal features and their realization on vocabulary items (Lardiere, 2005).

In terms of the present study, the Turkish-speaking English L2 children will need to figure out the feature specification of third person $-s$ and past tense $-e d$ in English and acquire their target-like morpho-phonological expression. More particularly, tense morphology in English is fusional and third person $-s$ encodes more features than past tense $-e d$ on a single morpheme, contrary to the monomorphemic nature of the Turkish tense and agreement paradigm. Third person $-s$ encodes [-past], [3p], and [+sing], whereas $-e d$ encodes [+past]. This feature composition of tense morphemes in English along with the different morphophonological paradigms of third person $-s$ and past tense $-e d$ may lead to an asymmetry in the acquisition of the two morphemes. At the same time, given that both the MSIH and the feature (re)assembly account suggest that L2 learners can have target-like mappings of forms and features but have difficulties finding the correct form in their lexicon, we may ascertain that the L2 learners have intact underlying representations associated with tense morphemes.

On the opposite end lie theories of L2 acquisition which postulate an incompleteness or deficit with underlying functional categories and argue that absence of a consistent morphological paradigm indicates that the underlying representations are lacking or are deficient, temporarily or permanently. Permanent impairment of underlying categories due to post-puberty exposure to the L2 is claimed by the Failed Functional Features Hypothesis (FFFH) (Hawkins \& Chan, 1997; Hawkins \& Hattori, 2006) and the Interpretability Hypothesis (IH) (Tsimpli, 2003). These theories argue that uninterpretable grammatical features, i.e. features void of semantic content (Chomsky, 1993), which are not present in the $\mathrm{L} 1$, are going to be problematic for L2 learners. These theories have primarily been articulated to account for adult L2 acquisition patterns, although they have recently been 
extended to child L2 acquisition (Tsimpli \& Dimitrakopoulou, 2007; Tsimpli \& Mastropavlou, 2008), and primarily focus on language combinations in which the L1 does not contain the grammatical category available in the L2. Given that Turkish contains a syntactic category for Tense, the FFFH and the IH cannot be addressed in this study. ${ }^{2}$

Another hypothesis arguing that optional production of grammatical morphemes indicates temporarily impaired or underspecified underlying syntactic categories related to these morphemes is the Minimal Trees Hypothesis (MTH) by Vainikka \& Young-Scholten (Vainikka \& Young-Scholten, 1996b; 1998a, 1998b, 2010). According to this account, the L1 plays a less important role and what seems to guide L2 acquisition is the L2 morphological paradigm. In this theory, there is a strong link between target-like L2 overt morphology and underlying syntactic categories, with the former triggering the latter. In the case of L2 acquisition, the trigger is free morphology, such as auxiliary and copula be, and not bound morphemes, namely third person $-s$ and past tense $-e d$, as is the case in L1 acquisition (Vainikka \& Young-Scholten, 1998b).

To date, only two studies have addressed this debate by comparing production with judgment of L2 children's comprehension of grammatical morphemes. Ionin \& Wexler (2002) report naturalistic and grammaticality judgment data from 20 Russian-speaking L2 children aged between 3;9 and 13;10 with less than three years of exposure to English. The

\footnotetext{
${ }^{2}$ We acknowledge that our study can be informative to a certain degree for the FFFH and the IH with respect to the predictions that these two theories make about the relationship between production and comprehension. Namely, the FFFH would predict that there should be no such asymmetry given that missing or optional morphology reflects impaired underlying representations (Franceschina, 2005). However, given that the participants in our study are pre-puberty L2 learners with the relevant formal feature grammaticalised in their L1, this study cannot adequately address these two theories.
} 
L2 children omitted third person $-s(78 \%)$ more than past tense $-e d(58 \%)$ in the production task. However, the authors do not focus on the asymmetry within bound morphology and they do not provide an explanation for it. In the grammaticality judgment task, the L2 children were at chance level when they had to reject uninflected or wrongly inflected thematic verbs (A-prime scores $=0.47$ and 0.56 respectively) and uninflected auxiliaries (Aprime score $=0.60$, but they were better at rejecting wrongly inflected auxiliaries (A-prime score $=0.80)$ or dropped - ing items $($ A-prime score $=0.81)$.

In the Paradis, et al. (2008) study, 24 TD children acquiring English as L2 aged between $4 ; 2$ and 7;10 (mean age: 5;7) with a mean of 9.5 months of exposure (range: $2-18$ months) were compared to 24 age-matched monolingual English-speaking children with SLI and 20 TD monolingual language controls. All children participated in the production and grammaticality judgment task from the Test for Early Grammatical Impairment (TEGI) (Rice \& Wexler, 2001). The TD L2 children performed significantly worse than the TD monolingual children and the monolingual children with SLI on the production of inflectional morphemes (third person $-s: \mathrm{L} 2 \mathrm{TD}=16 \%, \mathrm{~L} 1 \mathrm{SLI}=52 \%, \mathrm{~L} 1 \mathrm{TD}=42 \%$; past tense $-e d$ : $\mathrm{L} 2$ $\mathrm{TD}=20 \%, \mathrm{~L} 1 \mathrm{SLI}=47 \%, \mathrm{~L} 1 \mathrm{TD}=46 \%)$. In the grammaticality judgment task, both L2 TD children and L1 children with SLI performed at chance level, and they did not differ from each other in their ability to detect ungrammatical use of inflectional morphemes (A-prime score: $\mathrm{L} 2=0.46, \mathrm{SLI}=0.63) .^{3}$

Both Ionin \& Wexler (2002) and Paradis et al. (2008) argue against an (E)OI stage in child L2 acquisition primarily on the basis of the asymmetry in the acquisition between bound and

\footnotetext{
${ }^{3}$ Chance performance does not indicate that the children did not understand the task, as they were able to detect the ungrammaticality in the case of copula be and $d o$. Therefore, chance performance was restricted to bound tense morphology suggesting grammatically constrained behaviour.
} 
free morphology, which is not attested in L1 acquisition. This discrepancy between bound and free morphology has been explained in syntactic terms on the basis of the difference between 'overt' vs. 'covert' movement, the former operating in the case of copulas and auxiliaries, which overtly raise in English to check their tense features, and the latter in the case of lexical/thematic verbs, whose movement is not visible in the morpho-phonological spell out of the sentence (Ionin \& Wexler, 2002; Zobl \& Liceras, 1994). This discrepancy has also been explained in terms of input frequency and distributional consistency with be and $d o$ being more frequent and consistently distributed in the input than $-s$ and $-e d$ (Paradis et al., 2008).

The second argument against an (E)OI stage in L2 acquisition stems from the attested production - processing asymmetry. ${ }^{4}$ However, it should be noted that in both studies the grammaticality judgment scores of the L2 children were at chance level, indicating optionality in their underlying grammar and not a categorical and stable distinction between grammatical and ungrammatical sentences (Sorace, 2000), a pattern which is on a par with low or optional production.

A further important point is that so far the studies showing a high omission rate of tense morphology focus primarily on children with less than two years of exposure to English. An exception is a production study using TEGI with Turkish-English L2 children with exposure to English of more than three years (Marinis \& Chondrogianni, 2010). In this study, Marinis \& Chondrogianni (2010) found an asymmetry between the use of third person $-s$ and past tense $-e d$ with the latter exhibiting higher accuracy compared to the former (78.3 vs. $92.3 \%)$,

\footnotetext{
${ }^{4}$ Prévost (2003) has shown that child L2 learners of German make both missing surface inflection and optional infinitive errors. We would like to thank an anonymous reviewer for pointing this out to us. Unfortunately, the poor morphological verbal paradigm of English does not allow us to tease apart these two types of errors.
} 
and suggested that the morpho-phonological paradigm of the L2 affects L2 acquisition. This discrepancy was developmental and disappeared in the group of children that had four or more years of exposure (YoE), at which point more than half of the children reached ageappropriate norms for both morphemes. In terms of the types of errors produced by the L2 children, the majority constituted errors of omission for third person $-s$ and regular past tense $-e d$. Thus, this study showed that L2 children with more than three years of exposure are capable of acquiring tense and agreement morphemes in English. Furthermore, contrary to previous studies (Paradis et al., 2008) this study revealed a significant strong correlation between YoE and mastery of tense morphemes.

Turning to L2 processing, to date only two studies have examined how L2 children process morpho-syntax in real-time (Marinis, 2007; Marinis, 2008). These studies investigated how Turkish-English children process actives/passives and pronouns/reflexives in real-time and reported that L2 children are capable of using morpho-phonological cues similarly to L1 children despite the fact that the L2 children had lower grammatical and lexical abilities than the monolingual L1 age-matched controls and exhibited longer RTs. L2 children have been shown to have poorer lexical abilities than their monolingual peers (Bialystok, Craik \& Luk, 2008; Golberg et al. 2008; Kohnert, Kan \& Conboy, 2010), which may also affect their speed of processing of single word vocabulary. In a study with simultaneous bilingual Spanish-English children, Marchman, Fernald, \& Hurtado (2010) found that children with larger vocabularies exhibited faster and more efficient lexical access during real-time processing. This entails that if the sequential bilingual children in the present study have smaller vocabularies than their monolingual peers, then they may exhibit longer reaction-times in a real-time comprehension task. 


\section{PRESENT STUDY}

The present study examines how L2 children with more than three years of exposure produce and process on-line tense morphemes in comparison to L1 age-matched control children and children with SLI from Montgomery \& Leonard (1998, 2006). Given L2 children's reported problems with bound morphemes, in this study we focus on third person $-s$ and past tense $e d$ for the examination of tense morphemes, and progressive -ing and possessive $-s$ for the examination of non tense morphemes.

The main research questions we addressed are: 1) whether L2 children with more than three years of exposure reach age-appropriate scores in the production of tense morphemes, 2) whether the same L2 children are sensitive to the ungrammaticality induced by the omission of tense and non tense morphemes in an on-line processing task, and 3) whether processing of L2 morphemes differs for the children who are below vs. above the ageappropriate norms for their age in the production of third person $-s$ and past tense. Additionally, we indirectly examined whether or not the performance of the L2 children resembles that reported for the SLI children in Montgomery \& Leonard (1998, 2006).

Predictions for the present study

In the present study, it is not expected that Turkish-English child L2 learners will have impaired underlying representations due to the lack of the Tense category (Hawkins \& Chan, 1997; Tsimpli, 2003) given that Turkish contains a syntactic category for Tense. Non targetlike production may suggest impaired or underspecified syntactic categories (Vainikka \& Young-Scholten, 1996, 1998, 2010), which will be manifested as inability to make categorical distinctions between grammatical and ungrammatical sentences, and therefore, lack of sensitivity to the ungrammaticality related to the omission of these morphemes. If, on 
the other hand, the child L2 learners are sensitive to the ungrammaticality related to the omission of tense morphemes, then this would provide evidence for the MSIH (Haznedar \& Schwartz, 1997).

\section{METHOD}

\section{Participants}

Thirty nine typically developing (TD) sequential bilingual Turkish-speaking children and 28 TD monolingual English-speaking children participated in this study. The two groups were matched on age. The L2 children had a mean age of 7;7 (SD: 12 months; range: 6;2-9;7), and the L1 children a mean age of 7;3 (SD: 7 months; range: 6;0 - 8;4) $(\mathrm{F}(1,65)=4.012, \mathrm{p}>$ $\left.0.05, \eta^{2}=0.031\right)$. Both groups attended schools whose percentage of free school meals was well above the national average indicating a low socio-economic status.

All L2 children were from the Turkish community in London and were recruited from schools with a high density of Turkish-speaking children. The monolingual children were recruited from schools in Reading. The selection criteria for the L2 children were that the language spoken at home should be Turkish, the onset of systematic exposure to English should be three years or older, as indicated by nursery attendance, and the children should not have any history of speech and/or language delay or impairment. Additional information about the L2 children's years of exposure, quantity, and quality of input was collected through a parental and child questionnaire. This confirmed that none of the children had any history of speech and/or language delay or impairment, their parents were not concerned about their language development, and most children had an age of onset (AoO) around three years (mean: 3;3; SD: 8 months; range: $12-60$ months). The children's mean exposure to English was 4;3 (SD: 16 months; range: 20 - 81 months). Children participated in a battery of 
standardised and non-standardised assessments and experimental tasks examining various linguistic phenomena.

\section{Baseline language measures}

The present paper reports data from two background standardized tasks assessing comprehension of grammar, i.e. Test for Reception of Grammar 2 (TROG2) (Bishop, 2003), and single-word vocabulary, i.e. British Picture Vocabulary Scales II (BPVSII) (Dunn, Dunn, Whetton, \& Burley, 1997). In both tasks, children are presented with a four-picture panel and listen to a sentence or a word and are asked to indicate which picture matches the sentence or word they heard. The raw scores from both tasks are converted into standard scores on the basis of age appropriate norms for L1 children.

\section{Experimental tasks}

\section{Production task}

The screening task from the Test of Early Grammatical Impairment (TEGI) (Rice \& Wexler, 2001) was used to elicit tense morphemes. The TEGI has been standardized with 393 TD children and 444 children known to have SLI, between the ages of four to nine years. The screening task from the TEGI elicits third person singular $-s$, regular, and irregular past tense forms. For the elicitation of $-s$ children are shown pictures of professionals engaging in various activities and are asked to produce a verb form following a probe such as 'Here is a teacher. Tell me what she does'. The expected answer should be something like 'A teacher teaches'. For the elicitation of past tense, children are shown two pictures, one with children engaged in an activity and one with the activity completed. Past tense forms are prompted by the following lead-in sentences 'Here the boy is painting the fence. Now [pointing to the 
other picture] he is done. Tell me what he did'. The expected answer is 'The boy painted the fence'. The task includes ten trials for the production of $-s$ and 18 for the production of past tense, 10 for regular and eight for irregular verbs.

\section{Coding and scoring}

Responses were transcribed during the testing session on the TEGI scoring form. In order to have an overview regarding the L2 children's performance on tense morphemes and comparable scores to the L1 and SLI norms available in the TEGI manual, the children's responses were scored according to the procedure described in the manual. According to this procedure, the scores on the individual elicitation probes are calculated in percentage correct. Responses that are irrelevant or do not attempt the target form (e.g. present continuous for third person $-s$ or present tense for the past tense) are considered 'unscorable' and are excluded from the denominator for the score. For both probes, target-like responses are coded as correct and omissions of $-s$ or $-e d$ as incorrect. For irregular past tense forms, overregularizations are coded as correctly inflected forms. This scoring procedure follows theoretical assumptions according to which overregularizations denote knowledge of tense inflection and past tense rule formation. According to the TEGI manual and in the case of the past tense probe, when the children failed to produce the target verb, but still produced a verb of similar type, e.g. a regular verb, in the case of a target regular context, or an irregular verb, in the case of a target irregular context, then these were also included in the calculation. 


\section{On-line processing task}

To examine whether L2 children were sensitive to the omission of grammatical morphemes, we used an on-line word-monitoring task (Montgomery \& Leonard, 1998, 2006) in which half of the stimuli were sentences which contained tense (third person $-s$, past tense $-e d$ ) and non tense (progressive -ing and possessive 's) morphemes and the other half contained sentences, in which these morphemes were omitted. At the beginning of each trial, a target word was presented auditorily in isolation and at the same time its picture was presented visually on a laptop screen. This was followed by a lead-in sentence and the critical sentence which contained the critical word and the target monitored word, as shown in (4) below.

(4) Mary really likes to bake. Every day she bake(s) cakes and sometimes cookies and muffins.

Here the critical word was bake(s) and the target word was cakes. Participants were asked to press a response button as soon as they heard the monitored word in the sentence. If children are sensitive at detecting the ungrammaticality, then their RTs should be longer when the monitored noun follows an uninflected word than when it follows a fully inflected word.

The task included overall eight experimental conditions involving tense (third person $-s$ grammatical/ungrammatical, past tense -ed grammatical/ungrammatical) and non tense morphemes (progressive -ing grammatical/ungrammatical, possessive 's grammatical/ungrammatical). Each condition comprised 9 sentences giving rise to 72 experimental sentences in total. In the 6 conditions containing verbs, the same nine verbs were used across conditions (bake, chop, clean, cook, drop, kick, peel, play, wrap) either 
inflected or uninflected. Each critical verb was followed by a different noun in each condition giving rise to a total of 27 monitored nouns. 18 of the monitored nouns were in the plural form, 4 were mass nouns, and 5 singular count nouns. The possessive 's condition consisted of simple noun+noun combinations, e.g. Peter('s) books. The possessors were proper names $(n=4)$ and kinship terms $(n=5)$. Table 1 presents the distribution of verbs and nouns across conditions.

\section{INSERT TABLE 1 HERE}

All monitored nouns were controlled and matched across conditions for lemma frequency according to the CELEX database (Baayen, Piepenbrock \& Gulikers, 1995), imageability, position in sentence, and length measured in number of phonemes, syllables, vowel length within syllables, and age of acquisition of the lexical items ( $<6$ years of age). The pictures were also controlled for name agreement.

All verbs had to adhere to specific morpho-phonological and phonotactic criteria: i) verbs in the past tense had to be regular, (ii) the phonotactics of the past tense formation had to be legal, namely they had to contain word-ending clusters that also occur in mono-morphemic words, e.g. crossed (c.f. frost, mist), dropped (c.f. opt, apt) (Marshall \& van der Lely, 2006) ${ }^{5}$, and (iii) verbs that in the third person and past tense formation resulted in an extra syllable (e.g. wash-es, paint-ed) were excluded. In terms of allophones, for third person $-s$ and

\footnotetext{
${ }^{5}$ Mono-morphemically illegal clusters are clusters of regular past tense forms which cannot occur in other mono-morphemic words, and are therefore illegal in English phonology e.g. slammed, rushed and changed (Marshall \& van der Lely, 2006: 304). Marshall \& van der Lely (2006) found that children with SLI are sensitive to the legality of phonotactics, showing poor performance in the case of illegal phonotactics.
} 
possessive 's, /s/ and/z/ allophones were selected. For past tense, /t/ and /d/ allophones were selected.

The monitored nouns began with voiced stop consonants (/p, t, k, g, b/, etc.) because in these contexts the physical onset of the target is easier to identify (Kilborn \& Moss, 1996). Co-articulation between the monitored noun and the preceding word was avoided.

The task included also 18 filler items, 9 grammatical and 9 ungrammatical, and 18 catch trials. In the catch trials, the monitored noun is not included in the critical sentence, and participants are not expected to press the response button. Half of the filler items included case errors in possessive constructions, as in (5) below and catch trials involved omission of plural $-s$, as in (6) below.

5. $[\mathrm{DESK}] \quad$ Peter really likes his desk. He likes his/him desk by the window. 6. $[\mathrm{PEN}]$ Jack tried to sleep late this morning. He piled two pillow, blankets, and towels all over him.

All experimental and filler sentences were controlled for length in number of words ranging from 9 to 15 words for the critical sentence. The position of the monitored word was manipulated to appear in the fifth, seventh, or tenth position in the experimental sentences and in the fourth or eighth in the filler sentences. A comprehension question followed every third trial to ensure that participants were paying attention to the meaning of the sentences and were not only pressing the button to monitor words.

Two 54-item lists were created, each containing 27 experimental sentences, 9 filler sentences, and 9 catch trials. The grammatical and ungrammatical version of each experimental and filler sentence was assigned to different lists. The sentences were presented 
in a semi-randomized order, ensuring that experimental sentences involving the same critical word never appeared consecutively. The administration of the lists followed a within-subjects design, in which each participant was presented with both lists a week apart. The presentation of the lists was randomized in both the L1 and L2 groups in order to avoid any order of presentation effects.

\section{Procedure}

All L1 and L2 children participated in the baseline and the experimental tasks. The production task preceded the on-line processing task, in order to avoid raising the participants' awareness towards the phenomenon investigated by presenting them with ungrammatical sentences. The L1 and the L2 children were tested by the first author of this paper and a Turkish research assistant respectively in a quiet room at their schools. The wordmonitoring task was preceded by a practice session with 10 trials that could be repeated twice. The practice session intended to familiarize the children with the task. Children who completed the practice session successfully could continue participating in the experimental session. No child failed to complete the practice session or the experimental sessions. The administration of the production task lasted 20 minutes and each list of the word-monitoring task lasted approximately 20 minutes.

\section{RESULTS}

\section{Baseline tasks}

To examine whether the L2 children's overall comprehension of grammar and vocabulary differed from the L1 children's, we first analyzed the results from TROG2 and BPVSII, as shown in Table 2. 


\section{INSERT TABLE 2 HERE}

To examine differences between the two groups and the two tasks, we entered the standard scores of the two tasks into a repeated-measures ANOVA with Group (L1, L2) as a betweensubjects and Task (TROG2, BPVS) as a within subjects factor. This showed a main effect of Group $\left(F(1,63)=45.759, p<0.001, \eta^{2}=0.406\right)$, a main effect of Task $(F(1,63)=16.449, p$ $\left.<0.05, \eta^{2}=0.071\right)$, and an interaction between Group and Task $(F(1,63)=15.524, \mathrm{p}<$ 0.001, $\left.\eta^{2}=0.206\right)$. One-way ANOVAs showed that the L2 children were less accurate than the L1 children on both tasks (TROG2: $\left.F(1,64)=9.992, p<0.01, \eta^{2}=0.134\right)$; BPVSII: $F(1$, $\left.64)=120.558, \mathrm{p}<0.001, \eta^{2}=0.653\right)$ with a greater effect size in the case of vocabulary compared to grammar. Pairwise comparisons using Bonferroni correction showed that L1 children were equally good on TROG2 and BPVSII, but L2 children were significantly worse on BPVSII compared to TROG2 ( $\left.\mathrm{p}<0.001, \eta^{2}=0.335\right)$.

\section{Production of tense}

All children responded to more than half of the items and both groups produced mostly scorable utterances. Only $7 \%$ of the L1 children's responses and 7.4\% of the L2 children's responses were marked as 'unscorable' or 'not attempted' and there was no significant difference between the two groups in this respect. To address whether the L2 children in our study converge with L1 children in the production of tense marking, we calculated the children's accuracy for third person singular and past tense according to the scoring procedure of the TEGI, as shown in Figure 1. 


\section{INSERT FIGURE 1 HERE}

To examine differences between the two groups and the two morphemes, we entered the data into a repeated-measures ANOVA with Group $(\mathrm{L} 1, \mathrm{~L} 2)$ as a between-subjects and Morpheme (third person singular, past tense) as a within-subjects factor. This revealed a main effect of Group $\left(F(1,63)=6.102, p<0.05, \eta^{2}=0.066\right)$, a main effect of Morpheme $(F(1,63)=$ 5.842, $\left.\mathrm{p}<0.05, \eta^{2}=0.093\right)$, and no significant interaction between Group and Morpheme. One-way ANOVAs showed that the L2 children had a significantly lower accuracy $(77.1 \%)$, than the L1 children $(91.4 \%)$ in third person singular $-s\left(F(1,64)=3.861, p=0.05, \eta^{2}=\right.$ $0.081)$, and in past tense (L2: 86.2\%; L1: 96\%; $\left(\mathrm{F}(1,63)=4.940, \mathrm{p}<0.05, \eta^{2}=0.065\right)$. Paired samples t-tests revealed that L2 children were significantly less accurate on third person $-s$ compared to past tense $-e d(\mathrm{t}(37)=-2.146, \mathrm{p}<0.05)$. This discrepancy was not attested in the group of L1 children.

To examine possible relationships between YoE and the accuracy in the two grammatical Morphemes, we conducted nonparametric correlations (Spearman's rho). These showed a moderate positive correlation between YoE and third person singular $-s(\mathrm{r}(39)=0.413, \mathrm{p}<$ $0.01)$ and no correlation between YoE and past tense $(\mathrm{r}(38)=0.317, \mathrm{p}>0.05)$. To address whether the correlation between $\mathrm{YoE}$ and third person singular $-s$ is a genuine effect of $\mathrm{YoE}$ and not an effect of AoO, we conducted a further correlation and partialled out the AoO. The correlation between YoE and third person singular $-s$ remained significant $(\mathrm{r}(39)=0.405, \mathrm{p}$ $<0.05)$. 


\section{Word-monitoring task}

Initially, we calculated L1 and L2 children's accuracy on the comprehension questions. This was $90.4 \%$ and $79.2 \%$ respectively and showed that the two groups differed significantly from each other in terms of their comprehension accuracy $\left(F(1,64)=8.211, p<0.01, \eta^{2}=\right.$ 0.406). Reaction-time data from all sentences were first examined for extreme values, which were identified using SPSS boxplot procedure, and then for outliers defined as 2 SD above or below the mean per subject and item per condition. Extreme values were excluded from further analyses and outliers were replaced with the mean per subject and item per condition. This affected $9.3 \%$ of the L1 child data and $10.4 \%$ of the L2 child data and the two groups did not differ from each other in this respect.

Figures 2 and 3 present the mean RTs of the L1 and the L2 children in processing tense and non tense morphemes. To investigate differences between the two groups and between tense vs. non tense morphemes by the L1 and the L2 groups and whether the L2 children were sensitive to the ungrammaticality induced by morpheme omission, we entered the RT data into a repeated measures ANOVA with Group (L1, L2) as the between subjects factor and Morpheme type (tense, non tense), Morpheme (third person $-s$, past tense $-e d$, progressive -ing and possessive $-s$ ), and Grammaticality (grammatical, ungrammatical) as within subjects factors in a per participant $\left(\mathrm{F}_{1}\right)$ and per item $\left(\mathrm{F}_{2}\right)$ analysis. This revealed a main effect of Group $\left(F_{1}(1,64)=20.037, p<0.001, \eta^{2}=0.238 ; F_{2}(1,16)=75.968, p<\right.$ 0.001, $\eta^{2}=0.826$ ), reflecting longer RTs in the L2 compared to the L1 children, a main effect of Morpheme Type $\left(F_{1}(1,64)=33.868, p<0.001, \eta^{2}=0.346, F_{2}(1,16)=10.807, p<0.01\right.$, $\eta^{2}=0.403$ ) due to longer RTs in non tense compared with tense morphemes, and a main effect of Grammaticality $\left(F_{1}(1,64)=55.118, p<0.001, \eta^{2}=0.463 ; F_{2}(1,16)=48.868, p<\right.$ 
$0.001, \eta^{2}=0.753$ ) due to the longer RTs in the ungrammatical vs. the grammatical conditions. No other main effects or interactions were found to be significant, suggesting that the two groups were equally good at detecting the ungrammaticality induced by the omission of both tense and non tense morphemes. ${ }^{6}$

\section{INSERT FIGURE 2 HERE}

\section{INSERT FIGURE 3 HERE}

\section{Production-processing (a)symmetries}

To examine the relationship between production and processing, we assigned the L 2 children to two groups according to whether or not they were able to reach the criterion scores for third person $-s$ and past tense separately. ${ }^{7}$ Then we calculated their mean RTs for each tense

\footnotetext{
${ }^{6}$ An anonymous reviewer suggested that we carry out a repeated-measures ANCOVA with raw scores of the BPVS as a covariate to examine whether differences between the L1 and L2 children in terms of processing speed disappear if we control for their lexical abilities. Results revealed that indeed the main effect of Group became weaker when the raw scores of the BPVS were entered as co-variate $\left(F(1,62)=3.982, p=0.05, \eta^{2}=\right.$ $0.06)$ and this analysis gave rise also to an interaction between Morpheme Type and Morpheme. The main effect of Group disappeared when we conducted separate ANCOVAs for tense $\left(F(1,62)=2.918, p=0.093, \eta^{2}=\right.$ $0.044)$ and non tense morphemes $\left(F(1,62)=2.918, p=0.07, \eta^{2}=0.052\right)$, possibly due to lack of power, as the effect sizes indicate. However, the main effect of Grammaticality in tense morphemes was not cancelled out. This suggests that lexical abilities may affect speed of processing, but not the ability to process the ungrammaticality caused by the omission of tense morphemes.

${ }^{7}$ We used the criterion score as the cut-off point instead of adopting an arbitrary percentage because this is a more conservative measure. The use of the criterion score as a cut-off point also allowed us to have equal number of participants in each group, and thus, to carry out a meaningful statistical analysis.
} 
morpheme (third person $-s$ and past tense $-e d$ ) in the grammatical and ungrammatical version of the sentence. 20 out of the 39 L2 children were not able to reach the criterion score for third person $-s$ (below criterion: mean $=56.4 \%, \mathrm{SD}=23$, range $=0 \%-90 \%$; above criterion: mean $=98.9 \%, \mathrm{SD}=3.2$, range $=90 \%-100 \%)$. The children below the criterion score were at chance level $(\mathrm{t}(19)=1.229, \mathrm{p}>0.05)$ and differed significantly from the children who were able to reach criterion score $\left(\mathrm{t}(37)=-8.055, \mathrm{p}<0.001, \eta^{2}=0.625\right) .15$ out of $38 \mathrm{~L} 2$ children were not able to reach the criterion score for past tense (below criterion: mean $=68.2 \%, \mathrm{SD}=$ 29.8 , range $=0 \%-89 \%$; above criterion: mean $=97.9 \%, \mathrm{SD}=2.9$, range $=92.3 \%-100 \%)$, had optional production of past tense $(\mathrm{t}(14)=2.364, \mathrm{p}<0.05)$, and their production differed significantly from the children who were able to reach criterion score $(\mathrm{t}(36)=-3.838, \mathrm{p}<$ $\left.0.01, \eta^{2}=0.398\right)$

The L2 children who were below the criterion score for the third person $-s$ differed from the children above the criterion score both in terms of YoE (below criterion: mean $=3 ; 8, \mathrm{SD}$ $=12$ months, range $=1 ; 8-6 ; 9 ;$ above criterion: $4 ; 8, \mathrm{SD}=13$ months, range $=2 ; 2-6 ; 5 ; \mathrm{t}(38)$ $\left.=0.093, \mathrm{p}<0.05, \eta^{2}=0.104\right)$ and chronological age (below criterion: mean: $7 ; 2, \mathrm{SD}=8$ months, range $=6 ; 2-9 ; 1 ;$ above criterion: $8 ; 1, \mathrm{SD}=9$ months, range $=6 ; 3-9 ; 7 ; \mathrm{t}(38)=$ $\left.0.687, \mathrm{p}<0.01, \eta^{2}=0.056\right)$. That is, the children below criterion score for the third person $-s$ were younger and with less years of exposure. Conversely, the L2 children who were below the criterion score for past tense were of the same age as the children above the criterion score (below criterion: mean: 7;4, SD $=14$ months, range $=6 ; 2-9 ; 2 ;$ above criterion: $7 ; 8, \mathrm{SD}$ $=13$ months, range $\left.=6 ; 3-9 ; 7 ; \mathrm{t}(36)=-1.428, \mathrm{p}>0.05, \eta^{2}=0.098\right)$, but differed in terms of YoE (below criterion: mean: $3 ; 8, \mathrm{SD}=8$ months, range $=1 ; 8-6 ; 2 ;$ above criterion: $4 ; 6, \mathrm{SD}=$ 9 months, range $\left.=3 ; 2-6 ; 9 ; \mathrm{t}(36)=-2.047, \mathrm{p}<0.05, \eta^{2}=0.104\right)$. 
To compare the two groups in their ability to process the ungrammaticality due to omission of tense morphemes, we examined whether or not the children who were below the criterion score for third person $-s$ and past tense differed from the L2 children above the criterion score in their performance in the word-monitoring task, as shown in Figures 4 and 5.

\section{INSERT FIGURE 4 HERE}

\section{INSERT FIGURE 5 HERE}

The data for third person $-s$ and past tense were entered separately into repeated-measures ANOVAs with Group (below criterion score, above criterion score) as a between subjects factor and Grammaticality (grammatical, ungrammatical) as a within subjects factor in a per participant $\left(\mathrm{F}_{1}\right)$ and per item $\left(\mathrm{F}_{2}\right)$ analysis. For the third person $-s$, there was a significant main effect of Grammaticality $\left(F_{1}(1,37)=9.897, p<0.01, \eta^{2}=0.302 ; F_{2}(1,16)=9.030, p\right.$ $<0.01, \eta^{2}=0.361$ ) but no main effect of Group and no interaction between Group and Grammaticality, suggesting that the groups above and below the criterion score were sensitive to the ungrammaticality caused by the omission of $-s$. For past tense $-e d$ there was also a main effect of Grammaticality $\left(F_{1}(1,36)=5.091, p<0.05, \eta^{2}=0.124 ; F_{2}(1,16)=\right.$ $\left.6.225, \mathrm{p}<0.05, \eta^{2}=0.280\right)$, no main effect of Group and no interaction between Group and Grammaticality. This shows that both groups of children were capable of detecting the ungrammaticality related to $-e d$ omission. ${ }^{8}$

\footnotetext{
${ }^{8}$ As one of the anonymous reviewers pointed out, the two tasks did not have the same verbs because the on-line task did not contain any irregular verbs. Therefore, in principle the asymmetry could relate to specific lexical items. However, although TEGI includes both regular and irregular verbs, overregularizations of irregulars do not count as incorrect. Therefore, children are not penalised if they do not know the past tense of irregular verbs
} 


\section{DISCUSSION}

This is the first study to compare production with on-line comprehension of tense morphemes in the same L2 children and to examine whether they are capable of processing the ungrammaticality induced by the omission of tense and non tense morphemes in English. The aim of the study was to find out: 1) whether L2 children with more than three years of exposure reach age-appropriate scores in the production of tense morphemes, 2) whether the same L2 children are sensitive to the ungrammaticality induced by the omission of tense and non tense morphemes in an on-line processing task, 3) whether processing of L2 morphemes differs for the children who are below and above the age-appropriate norms. Finally, we indirectly compared the performance of the L2 children to that reported for the SLI children in Montgomery and Leonard (1998, 2006).

Firstly, the majority of the L2 children did not reach age-appropriate norms for the comprehension of grammar and single-word vocabulary. This confirms previous findings in the literature that sequential bilingual children are less accurate than L1 children in standardized assessments (Crutchley, Conti-Ramsden, \& Botting, 1997) and possess a smaller vocabulary than their monolingual peers (Mahon \& Crutchley, 2006; Oller \& Eilers, 2002).

\section{Production of tense morphemes in child L2 English}

\footnotetext{
and are rewarded whenever they use the regular past tense morpheme -ed. Thus, we do not think that the asymmetry between production-processing stems from the inclusion of irregular verbs, but we cannot rule out that specific lexical items may have contributed to this asymmetry.
} 
The L2 children in the present study had significantly lower performance in both the production of third person $-s$ and past tense $-e d$ than the L1 children. However, the L2 children's production rates for third person $-s$ and past tense $-e d$ were higher than the ones reported in previous studies with child L2 learners, who had less than three years of exposure (Haznedar, 2001; Ionin \& Wexler, 2002; Paradis et al., 2008), and they were similar to the results from the L2 children reported in Marinis \& Chondrogianni (2010).

The L2 children also displayed an asymmetry in the acquisition of third person $-s$ vs. past tense with nearly half of the children reaching age-appropriate norms for third person $-s$ (20/39) and more than half for past tense (23/38). This asymmetry emerged also in the correlations between the two morphemes and the YoE. A moderate correlation was found between third person $-s$ and YoE, suggesting that the L2 children's acquisition of the morpho-phonological paradigm of subject-verb agreement develops with exposure and that the L2 children are still in the developmental process. No correlation was found between past tense $-e d$ and YoE, reflecting L2 children's high performance on this morpheme $(86.2 \%)$ and the fact that the majority of the L2 children (23/38) had a score of $92.3 \%$ and above.

The question to ask at this point is why the L2 children display this asymmetry between third person $-s$ and past tense $-e d$. Asymmetrical patterns in the L2 acquisition of tense morphemes have been addressed for free morphemes, such as auxiliary and copula be, compared to bound morphemes, such as third person $-s$ and past tense $-e d$ (Goldschneider \& DeKeyser, 2001; Ionin \& Wexler, 2002; Jia \& Fuse, 2007; Paradis et al., 2008; Zobl \& Liceras, 1994), but not within bound morphemes. Uneven acquisition of grammatical morphemes can be accommodated in the L2 acquisition theories entertained in the present paper, namely the MSIH and the MTH. The MSIH accommodates uneven acquisition of grammatical morphemes by viewing variable use of morphology as a mapping problem of 
forms onto syntactic categories which remain intact (Haznedar \& Schwartz, 1997; Prévost \& White, 2000). In this respect, the focus is on the presence of the underlying structure rather than on what triggers variable production. Additionally, in the feature reassembly account, Lardiere (2005) suggests that given that the spell-out of the L2 morpho-phonological paradigm is a post-syntactic operation, the source of missing inflection lies in matching morpho-phonological features during this operation. The MTH, on the other hand, accounts for asymmetrical acquisition patterns by postulating a distinction between bound and free morphology for L2 acquisition (Vainikka \& Young-Scholten, 1998b). However, the two theories do not provide an explanation as to why certain morphemes are acquired before or after others. If a mapping problem is pursued following the MSIH, the question that arises is what affects the mapping of the correct morpho-phonological feature.

In the present study both third person singular $-s$ and past tense $-e d$ belong to the morphophonological paradigm of thematic verbs. However, the two morphemes differ both in terms of the formal features that they encode as well as with respect to the morpho-phonological spell-out of these formal features and the distributional consistency of their paradigms. Third person $-s$ in English is more complex in that it encodes [-past, 3p, +sing]. On the other hand, the regular suffix - ed encodes only [+past]. The asymmetry, thus, in the acquisition of third person $-s$ and past tense $-e d$ may derive from the more complex feature specification of third person $-s$ compared to past tense $-e d$ which renders the former more costly to access during computation of the expression by L2 learners (Hawkins, 2007). ${ }^{9}$ This account is compatible with the Distributed morphology framework (Halle \& Marantz, 1993), and thus, with the

\footnotetext{
${ }^{9}$ The complexity of the feature specification of third person $-s$ compared to the morpho-phonologically similar plural $-s$ has been put forward by Brown (1973) in order to account for the late acquisition of the former compared to the latter. We would like to thank one anonymous reviewer for pointing this out to us.
} 
MSIH. Additionally, whereas English past tense inflection has a consistent morphophonological form, the regular suffix $-e d$, for all persons and numbers, the agreement paradigm is morpho-phonologically poor with predominantly bare forms and with only third person singular $-s$ being overtly marked. Finally, from a functional perspective, third person $s$ is the realization of the $\mathrm{S}-\mathrm{V}$ agreement feature, which is required for grammatical reasons only and does not contribute to the meaning of the sentence. In contrast, past tense $-e d$ carries important information for the interpretation of the sentence, i.e. temporal reference, and its omission may lead to communication breakdown (VanPatten, 1996). ${ }^{10}$ In the present study these factors affect L2 children's production of third person $-s$ compared to past tense $-e d$, but not their ability to detect the ungrammaticality related to their omission in real-time, as the processing data indicate that the L2 children were equally sensitive to the omission of third person $-s$ and past tense $-e d$.

\section{Production-processing (a)symmetries in child L2 acquisition}

Turning now to the results from the word-monitoring task, both the L1 and the L2 children showed longer RTs in the ungrammatical compared to the grammatical conditions for tense and non tense morphemes. The results from the TD L1 children are in line with previous findings in Montgomery \& Leonard (1998, 2006), in which TD L1 children were sensitive to the ungrammaticality induced by morpheme omission and displayed no effect of morpheme type (tense vs. non tense).

Focusing on the relationship between production and on-line comprehension of tense morphemes in L2 acquisition, the results from the processing task indicate that the L2 children are sensitive to the ungrammaticality related to morpheme omission regardless of

\footnotetext{
${ }^{10}$ We would like to thank two anonymous reviewers for pointing this out to us.
} 
their optional and non target-like performance on the production of tense morphemes. This is particularly evident in the performance of the L2 children who failed to reach the criterion scores for third person $-s$ and past tense $-e d$. The children below the criterion score for third person singular $-s$, showed optional production rates (56.4\%) and significantly differed from the children above the criterion score $(98.9 \%)$. Furthermore, these children were younger and with less years of exposure than the children above the criterion score. However, they were able to process the ungrammaticality related to morpheme omission and did not differ from the children above the criterion score in their processing ability. The same results were found for past tense. The children below the criterion score were of equal age to the children above the criterion score, although they had less exposure. Despite the significantly lower production rates $(68.2 \%$ vs. $97.9 \%)$ they were able to process the ungrammaticality related to the omission of the $-e d$. How can we explain this asymmetry between sensitivity to ungrammaticality and lower production rates?

These results are in line with findings from (Paradis, 2010) and Paradis et al. (2008) who reported that simultaneous and sequential bilingual children performed better in a conscious judgment task compared to a production task. Paradis (2010) suggested that better performance on a conscious judgment task compared to production may be explained by two factors: 1) superior control abilities in bilinguals (Bialystok, 2007) that could affect their performance on a grammaticality task, and 2) competition cost in speech production processes affecting their accuracy in production. The word monitoring task used in the present study is a dual task and requires good executive function abilities relating to working memory and control for children to be able to perform the task. Similarly to conscious grammaticality judgment tasks, this task involves grammatical and ungrammatical sentences. However, unlike conscious grammaticality judgment tasks, it is an implicit task that measures 
the children's unconscious reaction to ungrammaticality. Since the reaction to ungrammaticality is unconscious and automatic, the grammaticality effect cannot be claimed to result from superior control abilities. That is, good control abilities are a pre-requisite for both L1 and L2 children to be able to perform the task, but the grammaticality effect does not require superior control abilities because it measures the children's automatic, and not their conscious response to ungrammaticality. Further evidence that the grammaticality effect does not require superior control abilities comes from the fact that both L1 and L2 children showed this sensitivity although L1 children are not supposed to have superior control abilities. In addition, L2 children had overall longer reaction times than L1 children, which provides further evidence that L2 children do not have better control abilities than L1 children. Therefore, we think that L1 and L2 children's sensitivity to ungrammaticality can better be explained as a reflection of their underlying grammatical competence and not as a result of superior control abilities. If this is true, the asymmetry between production and online processing could be caused by the L2 children's lower performance in the production task. Why should L2 children have a lower performance in the production task?

Their lower performance in production could be explained by competition cost (Paradis, 2010), but it could also be caused by the cost induced by output tasks related to spell-out in terms of the phonological instantiation and articulation. Either way, this could affect the children's production and as such provide an inaccurate reflection of their underlying grammatical representations. This idea needs to be tested in future research by using tasks that can tap into each one of those processes separately.

Finally, returning to the L2 acquisition theories entertained in the present study, the online data indicate that despite optional non target-like production, the underlying syntactic representations have been acquired by the L2 children. These findings are in line with the 
MSIH (Haznedar, 1997, Prévost \& White, 2000, Lardiere, 1998) and argue for a dissociation between overt morphological marking and underlying syntactic categories. Furthermore, the categorical distinction between grammatical and ungrammatical sentences in the on-line processing task provides evidence against the MTH (Vainikka \& Young-Scholten, 1998, 2010), since the MTH would predict no sensitivity to the ungrammaticality in the groups that are below the criterion score and display optional production of inflectional morphemes.

\section{L2 children vs. children with SLI}

The final aim of the present study revolved around whether or not the performance of the L2 children resembles the one reported for the children with SLI in Montgomery and Leonard (1998, 2006). This can shed light on possible similarities and differences between the two populations.

Firstly, the results from the L2 children contrast with the findings from the children with SLI in the Montgomery \& Leonard studies. In Montgomery \& Leonard (1998; 2006) the children with SLI were not capable of processing the ungrammaticality related to the omission of tense morphemes, but were only sensitive to the omission of progressive -ing. In addition, they showed poorer performance in judging grammatical and ungrammatical sentences containing tense morphemes than the TD age-matched children, but their performance was relatively high (86.5\% vs. $94.9 \%)$. Target-like performance in the grammaticality judgment task was restricted to the progressive -ing, indicating that children with SLI do not lack metalinguistic abilities altogether, but metalinguistic abilities affect grammatical structures differentially (Montgomery \& Leonard, 1998, 2006; Rice \& Wexler, 2001; Rice, Wexler, \& Redmond, 1999). 
The L2 children of the present study were capable of processing the ungrammaticality related to the omission of both tense and non tense morphemes, including the group of L2 children that showed optionality in the production of tense morphemes. This was also despite the fact that the L2 children in the present study were younger than the children with SLI in the previous studies.

A point of similarity between the two populations was that both the L2 children and the children with SLI exhibited overall longer RTs than their monolingual TD age-matched peers. However, longer RTs may be caused by different factors in the two groups. Children with SLI have been shown to have longer RTs in language and non-language tasks and have been claimed to be caused by limitations in the general processing capacity (Kail, 1994). This slow processing and lack of automaticity (Paradis \& Gopnik, 1997) may have an impact on their ability to detect grammaticality errors in real-time, but may also reflect impaired underlying grammar. On the other hand, in L2 children, speed of processing could be related to vocabulary size affecting the speed of lexical retrieval due to their low proficiency (Bialystok et al. 2008). The two background tasks assessing the children's comprehension of grammar and single-word vocabulary showed that the L2 children were less proficient than the L1 children, they failed to reach age-appropriate norms, and their performance on vocabulary was significantly lower than on grammar. In addition, the effect of speed of processing was reduced when we used the vocabulary scores are co-variates, suggesting that speed of processing in L2 children is modulated by vocabulary size.

Therefore, the differences observed between the L2 children and the children with SLI with regards to their ability to process tense morphemes suggests differences between the two groups in the nature of their processing system and underlying grammatical representations. For children with SLI, non-target-like production seems to reflect impaired underlying 
representations. For the L2 children, on the other hand, non target-like production does not entail impaired underlying representations, despite low general proficiency and inability to reach age-appropriate norms in the target structures.

\section{CONCLUSIONS}

The present study addressed the question whether or not English L2 children with more than three years of exposure are capable of reaching age-appropriate norms and explored the relationship between production and on-line processing of tense and non tense morphemes in English. The L2 children's performance was compared with the performance of children with SLI from Montgomery \& Leonard (1998, 2006). The L2 children were less accurate than L1 children in the comprehension of grammar and single-word vocabulary and did not reach age-appropriate norms in the production of tense morphemes. Although they showed longer RTs than the L1 children, their pattern of performance was similar to the L1 children, i.e. they were sensitive to the ungrammaticality induced by the omission of tense and non tense morphemes. The production and processing asymmetry of tense morphemes by the L2 children in the present study are more compatible with the MSIH than with the MTH, because despite their optional production of tense morphemes, the L2 children were sensitive to the ungrammaticality induced by the omission of third person singular $-s$ and past tense $e d$ when processing sentences on-line. Finally, the L2 children in the present study differed from the children with SLI in that the latter were unable to detect the ungrammaticality induced by the omission of $-s$ and $-e d$. This suggests that despite the low accuracy scores that both groups exhibit in the production of bound morphemes (Paradis, 2005), they differ in the nature of their processing system and their underlying grammatical representation. 


\section{References}

Baayen, R. H., Piepenbrock, R., \& Gulikers, L. (1995). The CELEX lexical database (CD-ROM) (Version 2.5 (English)). Philadelphia: Linguistic Data Consortium, University of Pennsylvania.

Bialystok, E. (2007). Cognitive effects of bilingualism: How linguistic experience leads to cognitive change. International Journal of Bilingual Education and Bilingualism, 10, 210-223.

Bialystok, E., Craik, F.I.M. \& Luk, G (2008). Lexical access in bilinguals: Effects of vocabulary size and executive control. Journal of Neurolinguistics, 21, 522-538.

Bishop, D. V. M. (2003). Test for reception of grammar, Version 2 (TROG-2). London: The Psychological Corporation.

Brown, R. (1973). A first language: The early stages. London: Penguin Books.

Chomsky, N. (1993). A minimalist program for linguistic theory. In K. H. \& S. J. Keyser (Eds.), The view from building 20 (pp. 1-52). Cambridge, MA: MIT Press.

Crutchley, A., Conti-Ramsden, G., \& Botting, N. (1997). Bilingual children with specific language impairment and standardised assessments: preliminary findings from a study of children in language units. International Journal of Bilingualism, 1, 117-134.

de Villiers, J., \& de Villiers, P. (1973). A cross sectional study of the acquisition of grammatical morphemes in child speech. Journal of Psycholinguistic Research, 2, 267-278.

Dulay, H., \& Burt, M. (1973). Should we teach children syntax? Language Learning 23, $245-$ 258.

Dulay, H., Burt, M., \& Krashen, S. (1982). Language two. Oxford: Oxford University Press.

Dunn, L. M., Dunn, L. M., Whetton, C., \& Burley, J. (1997). The British Picture Vocabulary Scale (2nd ed.). Windsor: NFER-Nelson.

Franceschina, F. (2005). Fossilized second language. The acquisition of grammatical gender. Amsterdam: John Benjamins.

Göksel, A., \& Kerslake, C. (2005). Turkish: A compehensive grammar. London: Routledge.

Goldscheider, J.M. \& DeKeyser, R. M. (2001). Explaining the "natural order of L2 morpheme acquisition" in English: a meta-analysis of multiple determinants. Language Learning, 5, $1-50$.

Grüter, T. (2005). Comprehension and production of French object clitics by child second language learners and children with specific language impairment. Applied Psycholinguistics, 26, 363-391.

Halle, M., \& Marantz, A. (1993). Distributed morphology and the pieces of inflection. In K. Hale \& S. J. Keyser (Eds.), The view from building 20 (pp. 111-176). Cambridge MA: MIT Press.

Hawkins, R. (2007). Emergent and innate sources of knowledge in the early L2 acquisition of English verbal morphology. In A. Radford (Ed.), Martin Atkinson - The minimalist muse (pp. 135-156). Essex: University of Essex.

Hawkins, R., \& Chan, C. Y. (1997). The partial availability of Universal Grammar in second language acquisition: The 'failed functional features hypothesis'. Second Language Research 13, 187-226. 
Hawkins, R., \& Hattori, H. (2006). Interpretation of English multiple wh-questions by Japanese speakers: A missing uninterpretable feature account. Second Language Research, 22, 269-301.

Haznedar, B. (2001). The acquisition of the IP system in child L2 English. Studies in Second Language Acquisition, 23, 1-39.

Haznedar, B., \& Schwartz, B. (1997). Are there optional infinitives in child L2 acquisition? In E. Hughes, M. Hughes, \& A. Greenhill (Eds.), Proceedings of the 21st Annual Boston University Conference on Language Development (pp. 257-268). Somerville, MA: Cascadilla Press.

Ionin, T., \& Wexler, K. (2002). Why is 'is' easier than '-s'?: acquisition of tense/agreement morphology by child second language learners of English. Second Language Research, $18,95-136$.

Jia, G., \& Fuse, A. (2007). Acquisition of English grammatical morphology by native Mandarinspeaking children and adolescents: Age-related differences. Journal of Speech Language and Hearing Research, 50, 1280-1299.

Kail, R. V. (1994). A method for studying the generalized slowing hypothesis in children with specific language impairment. Journal of Speech and Hearing Research, 37, 418-421.

Kilborn, K., \& Moss, H. (1996). Word Monitoring. Language and Cognitive Processes, 11, 689694.

Kohnert, K., Kan, P. F. \& Conboy, B. T. (2010). Lexical and grammatical associations in sequential bilingual preschoolers. Journal of Speech, Language, and Hearing Research, 53, 684-698.

Lardiere, D. (1998a). Case and Tense in the 'fossilized' steady state. Second Language Research, $14,1-26$.

Lardiere, D. (1998b). Dissociating syntax from morphology in a divergent L2 end-state grammar. Second Language Research, 14, 359-375.

Lardiere, D. (2005). On morphological competence. In L. Dekydtspotter, R.A. Sprouse \& A. Liljestrand. Proceedings of the 7th Generative Approaches to Second Language Acquisition Conference (GASLA 2004) (pp. 178-192). Somerville, MA: Cascadilla Proceedings Project.

Lardiere, D. (2009). Some thoughts on the contrastive analysis of features in second language acquisition. Second Language Research, 25, 173-227.

Mahon, M., \& Crutchley, A. (2006). Performance of typically-developing school-age children with English as an additional language on the British Picture Vocabulary Scales II. Child Language Teaching and Therapy, 22, 333-351.

Marchman, V. A., Fernald, A., \& Hurtado, N. (2010). How vocabulary size in two languages relates to efficiency in spoken word recognition by young Spanish-English bilinguals. Journal of Child Language, 37, 817-840.

Marinis, T. (2007). On-line processing of passives in L1 and L2 children. In A. Belikova, L. Meroni \& M. Umeda (Eds.), Proceedings of the 2 nd Conference on Generative Approaches to Language Acquisition North America (GALANA) (pp. 265-276). Somerville, MA: Cascadilla Proceedings Project.

Marinis, T. (2008). On-line processing of sentences involving reflexive and non-reflexive pronouns in L1 and L2 children. In A. Gavarró Algueró \& M. J. Freitas (Eds.), Language 
acquisition and development. Proceedings of GALA 2007. (pp. 348-358). Cambridge: Cambridge Scholars Publishing

Marinis, T., \& Chondrogianni, V. (2010). Production of tense marking in successive bilingual children: When do they converge with their monolingual peers? International Journal of Speech-Language Pathology, 12, 19-28.

Marinis, T., \& Chondrogianni, V. (2011). Comprehension of reflexives and pronouns by child L2 learners. Journal of Neurolinguistics, 24, 202-212.

Marshall, C. R., \& van der Lely, H. K. J. (2006). A challenge to current models of past tense inflection: The impact of phonotactics. Cognition, 100, 302-320.

Montgomery, J. W., \& Leonard, L. B. (1998). Real-Time inflectional processing by children with specific language impairment: Effects of phonetic substance. Journal of Speech Language and Hearing Research, 41, 1432-1443.

Montgomery, J. W., \& Leonard, L. B. (2006). Effects of acoustic manipulation on the real-time inflectional processing of children with Specific Language Impairment. Journal of Speech Language and Hearing Research, 49, 1238-1256.

Oller, D. K., \& Eilers, R. E. (2002). Language and literacy in bilingual children. London: Multilingual Matters.

Paradis, \& Gopnik, M. (1997). Compensatory strategies in genetic dysphasia: Declarative memory. Journal of Neurolinguistics, 10, 173-185.

Paradis, J. (2005). Grammatical morphology in children learning English as a second language: Implications of similarities with Specific Language Impairment. Language, Speech and Hearing Services in the Schools, 36, 172-187.

Paradis, J. (2010). Bilingual children's acquisition of English verb morphology: Effects of language dominance, structure difficulty, and task type. Language Learning, 60, 651-680.

Paradis, J., Rice, M. L., Crago, M., \& Marquis, J. (2008). The acquisition of tense in English: Distinguishing child second language from first language and specific language impairment. Applied Psycholinguistics, 29, 689-722.

Prévost, P. (2003). Truncation and missing inflection in initial child L2 German. Studies in Second Language Acquisition, 25, 65-97.

Prévost, P., \& White, L. (2000). Missing Surface Inflection or Impairment in second language acquisition? Evidence from tense and agreement. Second Language Research, 16, 103133.

Rice, M. L., \& Wexler, K. (2001). Rice/Wexler test of early grammatical impairment. New York The Psychological Corporation, Hartcourt Assessment Company.

Rice, M. L., Wexler, K., \& Hershberger, S. (1998). Tense over time: The longitudinal course of tense acquisition in children with specific language impairment. Journal of Speech and Hearing Research, 38, 850 - 863.

Rice, M. L., Wexler, K., \& Redmond, S. (1999). Grammaticality judgments of an extended optional infinitive grammar: Evidence from English-speaking children with specific language impairment. Journal of Speech, Language, and Hearing Research, 42, 943-961.

Sorace, A. (2000). Syntactic optionality in non-native grammars. Second Language Research, 16, 93-102.

Tsimpli, I. M. (2003). Clitics and articles in L2 Greek. In J. M. Liceras, H. Zobl \& H. Goodluck (Eds.), Proceedings of the 6th Generative Approaches to Second Language Acquisition 
Conference (GASLA 2002) (pp. 331-339). Somerville, MA: Cascadilla Proceedings Project.

Tsimpli, I. M., \& Dimitrakopoulou, M. (2007). The Interpretability Hypothesis: evidence from wh-interrogatives in second language acquisition. Second Language Research, 23, 215242.

Tsimpli, I. M., \& Mastropavlou, M. (2008). Feature Interpretability in L2 Acquisition and SLI: Greek Clitics and Determiners. In H. Goodluck, J. Liceras \& H. Zobl (Eds.), The role of formal features in second language acquisition (pp. 143-183). London: Routledge.

Vainikka, A., \& Young-Scholten, M. (1996a). The early stages in adult L2 syntax: additional evidence from Romance speakers. Second Language Research, 12, 140-176.

Vainikka, A., \& Young-Scholten, M. (1996b). Gradual development of L2 phrase structure. Second Language Research, 12, 7-39.

Vainikka, A., \& Young-Scholten, M. (1998a). The initial state in the L2 acquisition of phrase structure. In S. Flynn, G. Martohardjono \& W. O'Neil (Eds.), The generative study of second language acquisition (pp. 17-88). Somerville MA: Laurence Erlbaum.

Vainikka, A., \& Young-Scholten, M. (1998b). Morphosyntactic triggers in adult SLA. In M.-L. Beck (Ed.), Morphology and its interfaces in second language knowledge (pp. 89-114). Amsterdam: John Benjamins.

Vainikka, A., \& Young-Scholten, M. (2010). All acquisition begins with the projection of a bare verb phrase. Applied Psycholinguistics, 31, 332-339.

VanPatten, B. (1996). Input processing and grammar instruction in second language acquisition. Norwood, NJ: Ablex.

Wexler, K. (1994). Optional infinitives, head movement and the economy of derivations in child grammar. In D. Lightfoot \& N. Hornstein (Eds.), Verb movement (pp. 305-350). Cambridge: Cambridge University Press.

Wexler, K. (1998). Very early parameter setting and the unique checking constraint: A new explanation of the optional infinitive stage. Lingua, 106, 23-79.

White, L. (2003). Second language acquisition and universal grammar. Cambridge: Cambridge University Press.

White, L. (2009). Some questions about feature re-assembly. Second Language Research, 25, 343-348.

Zobl, H., \& Liceras, J. (1994). Functional categories and acquisition orders. Language Learning, $44,159-180$. 
Table 1. Verbs and nouns per condition

\begin{tabular}{|c|c|c|c|c|c|}
\hline Critical word & & Morpheme & & Critical word & Morpheme \\
\hline Verb & Third person $-s$ & Past tense -ed & Progressive -ing & Noun & Possessive $-s$ \\
\hline play & drums & games & cards & father & $\operatorname{dog}$ \\
\hline drop & plates & cups & bottles & Peter & books \\
\hline cook & beans & fish & turkey & uncle & car \\
\hline bake & cakes & biscuits & bread & Mary & bike \\
\hline peel & lemons & pears & apples & Kate & boots \\
\hline kick & balls & balloons & stones & brother & glasses \\
\hline clean & tables & shoes & windows & mother & kitten \\
\hline wrap & paper & boxes & towels & sister & dresses \\
\hline chop & carrots & leaves & onions & Jake & rucksack \\
\hline
\end{tabular}


Table 2: Results from the Test for Reception of Grammar 2 (TROG2) and the British Picture Vocabulary Scale II (BPVSII)

\begin{tabular}{|c|c|c|c|c|c|c|c|}
\hline & & \multicolumn{3}{|c|}{$\mathrm{L} 1(N=28)$} & \multicolumn{3}{|c|}{$\mathrm{L} 2(N=39)$} \\
\hline & & Mean & SD & Range & Mean & SD & Range \\
\hline \multirow{3}{*}{ 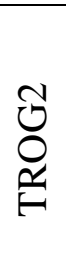 } & Raw score & 13.2 & (1.8) & $10-18$ & 11.2 & (3.6) & $1-16$ \\
\hline & Standard score & 99.3 & (9.3) & $85-120$ & 89.6 & $(15.2)$ & $55-111$ \\
\hline & Z-score & 0 & (0.6) & $-1.0-1.3$ & -1.0 & $(-0.7)$ & $-3.0-0.9$ \\
\hline \multirow{3}{*}{$\begin{array}{l}= \\
\infty \\
2 \\
\frac{1}{n}\end{array}$} & Raw score & 75.7 & $(11.4)$ & $46-91$ & 54 & $(11.4)$ & $31-77$ \\
\hline & Standard score & 101.3 & (7.3) & $87-115$ & 81.6 & (7.3) & $65-101$ \\
\hline & Z-score & -0.5 & (2.0) & $-0.9-1.0$ & -1.2 & $(0.5)$ & $-2.3-0.1$ \\
\hline
\end{tabular}


Figure 1. Accuracy on the production of tense morphemes

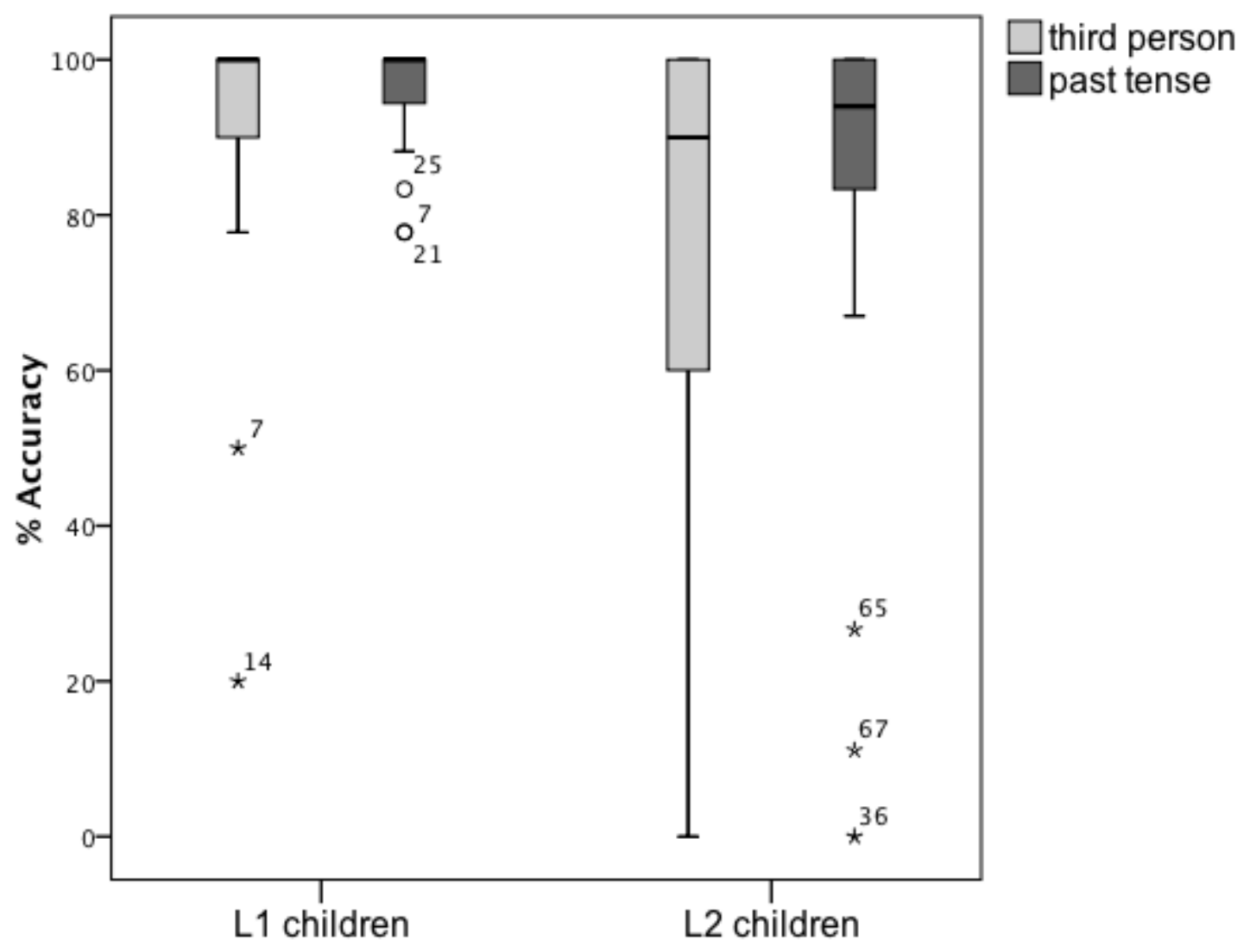


Figure 2. Reaction-times in milliseconds for tense morphemes

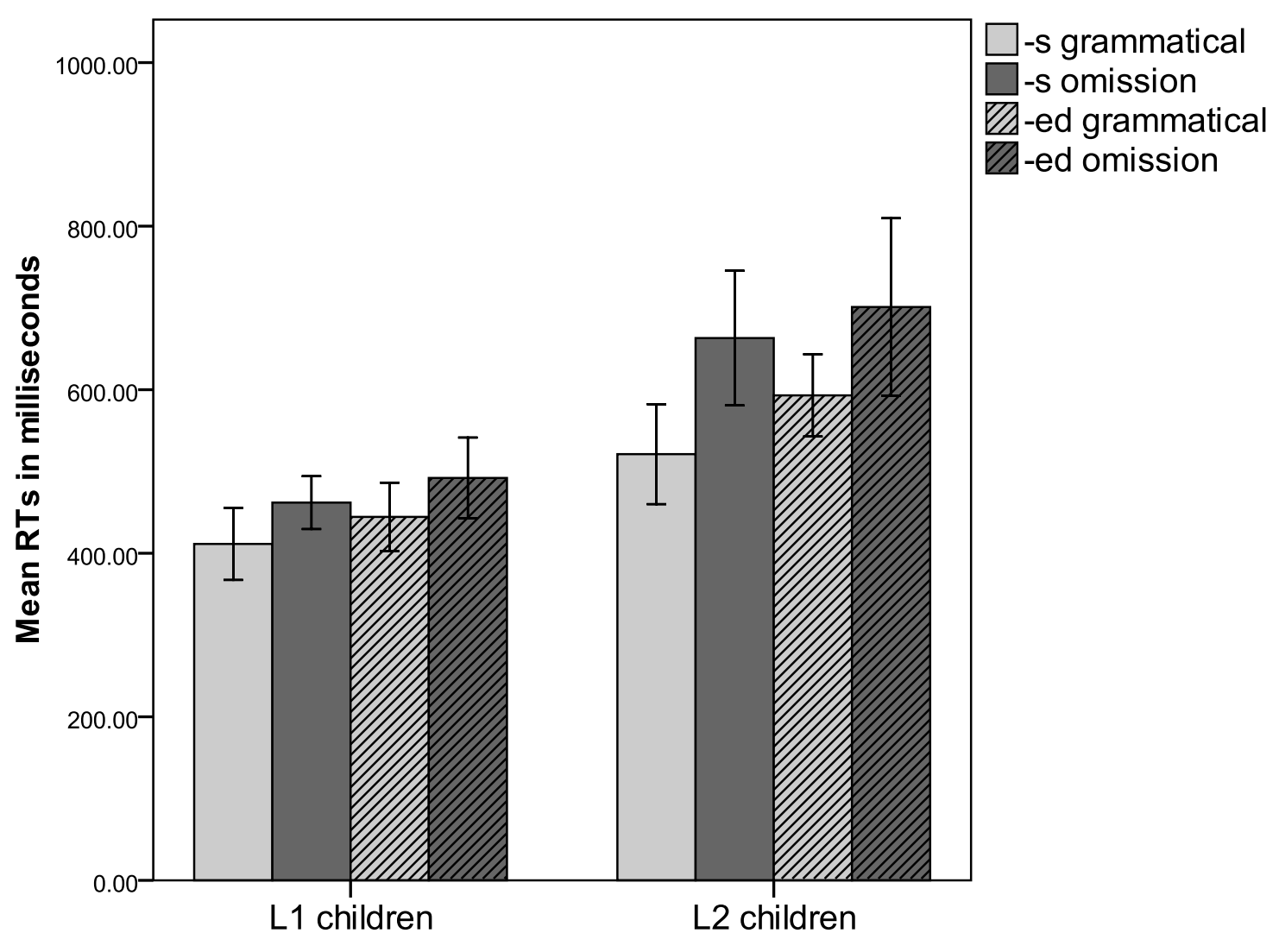


Figure 3. Reaction-times in milliseconds for non tense morphemes

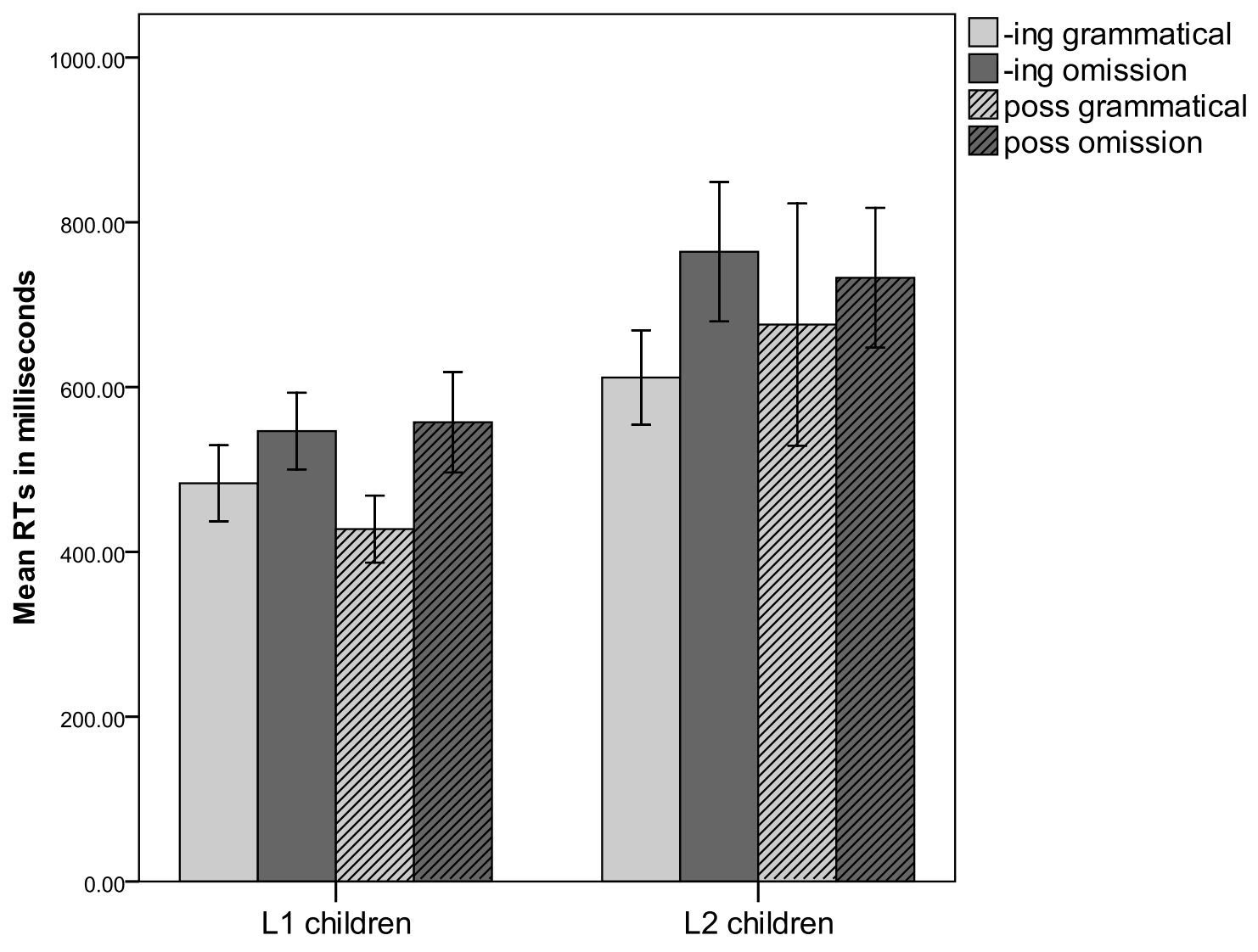


Figure 4. Reaction times in milliseconds for the children below and above the criterion score for third person $-S$

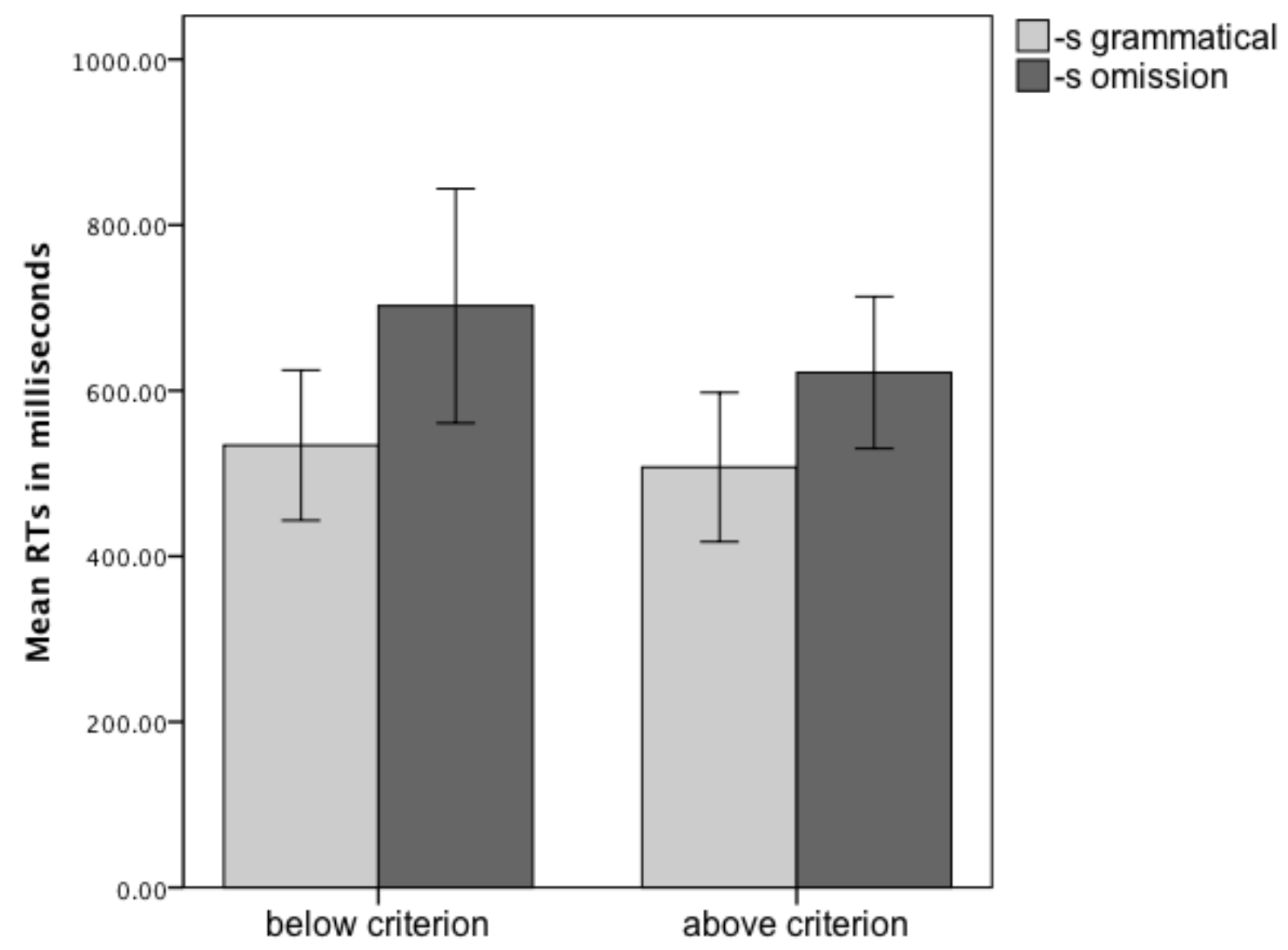


Figure 5. Reaction times in milliseconds for the children below and above the criterion for past tense

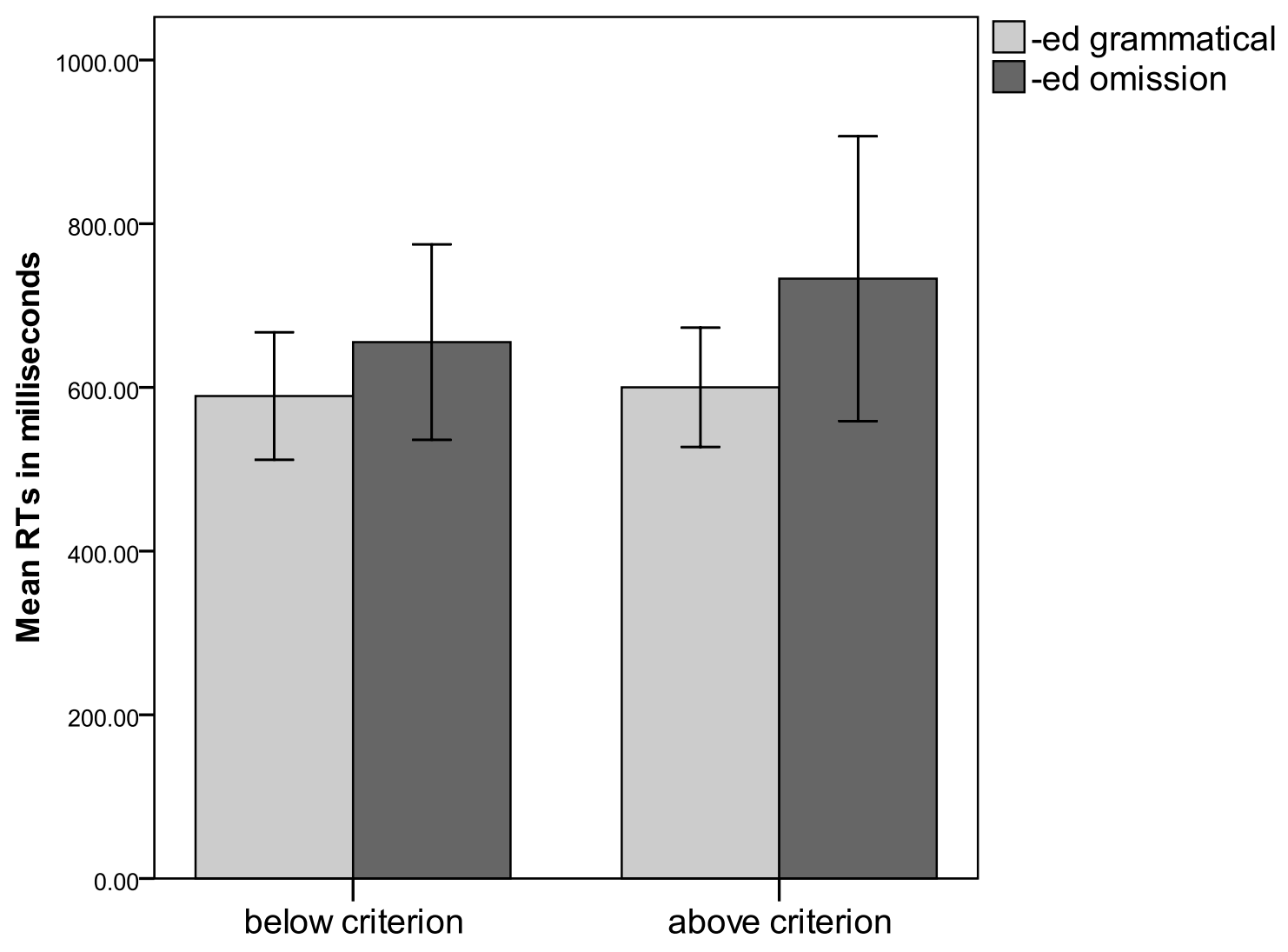

